\title{
A RELAÇÃO ENTRE PORTAL DA TRANSPARÊNCIA E CONTROLE SOCIAL NO MEIO ACADÊMICO
}

\author{
Alessandra Cristina Rubio'; Rosimar Cristina Seze²; Thiago Silva Guimarães ${ }^{3}$. \\ ${ }^{1}$ Doutoranda em Ciências Contábeis e Administração, FUCAPE Business School (FUCAPE), \\ Vitória-ES. \\ ${ }^{2}$ Bacharel em Ciências Contábeis, Universidade do Estado de Mato Grosso (UNEMAT), Nova \\ Mutum-MT. \\ ${ }^{3}$ Doutorando em Ciências Contábeis e Administração, FUCAPE Business School (FUCAPE), \\ Vitória-ES.
}

DOI: 10.47094/ICONACON.2021.5

\begin{abstract}
RESUMO
O presente artigo tem o propósito de averiguar se os universitários dos cursos de Ciências Contábeis e Administração do Campus de Nova Mutum - MT, usam o Portal da Transparência do município de Nova Mutum - MT. Para atender os objetivos propostos, foi aplicado um questionário entre os acadêmicos dos cursos de Ciências Contábeis e Administração, e os dados coletados foram submetidos a uma análise de caráter quanti-qualitativo. Os números mostram que, é baixo o índice de acadêmicos que acessam o Portal da Transparência, uma parte deles apresentaram dificuldades para obter as informações desejadas. Conclui-se que, o nível de participação cidadã entre os acadêmicos no que se refere ao controle social e fiscalização da gestão pública é baixo. Foi possível perceber ainda, que quando o acadêmico tem de certa forma algum contato com as questões públicas, por ter cursado disciplinas que abordassem a gestão pública, esse nível melhora.
\end{abstract}

PALAVRAS-CHAVE: Portal da Transparência. Acadêmicos. Controle social.

ÁREA TEMÁTICA: Administração pública.

\section{INTRODUÇÃO}

Nas sociedades democráticas são garantidos legalmente aos cidadãos direitos de participação na gestão pública. Entre esses direitos estão o de acesso à informação, o da transparência e o da participação da tomada de decisões que afetará o coletivo (CRUZ et al., 2012).

Portanto, é de suma importância para a sociedade que o cidadão exerça os seus direitos democráticos, e participe efetivamente da gestão pública, cobrando, fiscalizando e contribuindo para uma melhor administração dos recursos públicos (ANDRADE; CASTRO; PEREIRA, 2012). 
A formação acadêmica vai além dos saberes técnicos e científicos, é uma formação que busca contribuir para a construção de uma sociedade participativa, em que os cidadãos agem de maneira crítica e consciente do seu papel no exercício da cidadania e da democracia. Conforme Niskier, (1997, p. 33-34) "[...] a constituição, além de estabelecer a educação como direito e dever do Estado, especifica também o preparo da pessoa para o exercício da cidadania." Portanto, esperase que a formação acadêmica contribua para a formação de um profissional que participe ativamente da comunidade em que está inserido, contribuindo para o bem comum social (MATIAS-PEREIRA, 2010).

O Portal de Transparência é um instrumento pelo qual o cidadão tem acesso à informações referentes à gestão pública, podendo portanto, ser utilizado pelo universitário como uma fonte de pesquisa no intuito de tornar-se conhecedor das práticas de gestão pública do município.

Diante dessa temática surge uma problemática que indaga se os universitários dos cursos de Ciências Contábeis e Administração do Campus de Nova Mutum - MT da Universidade do Estado de Mato Grosso - UNEMAT, usam o Portal de Transparência do município de Nova Mutum como fonte de informações quanto à Administração Pública.

Para responder a problemática essa pesquisa se desenvolve sob o objetivo geral de averiguar se os universitários dos cursos de Ciências Contábeis e Administração do Campus de Nova Mutum - MT, usam o Portal da Transparência do município de Nova Mutum - MT, e se o Portal atende às necessidades dos mesmos quanto ao fornecimento de informações acerca da Administração Pública. E ainda, objetiva especificamente verificar o índice de universitários que acessam o Portal da Transparência, analisar se o mesmo é um instrumento capaz de atender às necessidades dos acadêmicos, além de analisar se as disciplinas voltadas para a área pública têm influenciado na postura dos acadêmicos no que se refere a prática do controle social.

Neste sentido, a presente pesquisa trará discussões e reflexões acerca da atuação cidadã do universitário na comunidade em que vive.

\section{METODOLOGIA}

A presente pesquisa é de natureza quantitativa e qualitativa. Conforme Zanella (2012, p.75) a pesquisa quantitativa "procura medir e quantificar os resultados da investigação, elaborando-os em dados estatísticos." Através da quantificação numérica mensura-se o comportamento em relação à opiniões, atitudes e preferências (ZANELLA, 2012).

Quanto aos objetivos se enquadra como uma pesquisa exploratória. Os estudos exploratórios "possibilitam aumentar o conhecimento do pesquisador sobre os fatos, permitindo a formulação mais precisa de problemas, criar novas hipóteses e realizar novas pesquisas mais estruturadas" (OLIVEIRA, 2011, p.20).

Portanto, essa pesquisa é caracterizada pelo método quanti-qualitativo, por meio de uma pesquisa de campo. 
A coleta de dados da pesquisa se deu por meio de questionário com perguntas comportamentais, contendo 09 questões fechadas e 01 questão aberta. O questionário foi aplicado entre os acadêmicos matriculados nos $1^{\circ}, 2^{\circ}, 7^{\circ}$ e $8^{\circ}$ semestres no período 2018/1, dos Cursos de Ciências Contábeis e Administração do Campus de Nova Mutum da Universidade Estadual de Mato Grosso - UNEMAT.

O público alvo desta pesquisa está intencionalmente delimitado entre os acadêmicos dos $1^{\circ}$, $2^{\circ}, 7^{\circ}$ e $8^{\circ}$ semestres no período $2018 / 1$, com o objetivo de verificar se o fato de cursar disciplinas voltadas para a área pública interfere no resultado da pesquisa. Considerando que, os acadêmicos do $7^{\circ}$ e $8^{\circ}$ semestres já terão cursados as disciplinas da área pública.

\section{RESULTADOS E DISCUSSÕES}

Conforme Prefeitura Municipal de Nova Mutum (2018), criou-se o Portal da Transparência, em atendimento à Lei Complementar 131/2009 e à Lei 12.527/2011, chamada de 'Lei de Acesso à Informação', com o propósito de regulamentar o direito constitucional de acesso dos cidadãos às informações públicas. Ainda de acordo com a Prefeitura, por este canal o cidadão poderá acompanhar de forma dinâmica a aplicação dos recursos públicos da Prefeitura, compreendendo as receitas transferidas para o município e a execução das despesas, sendo oferecidas outras informações de interesse do cidadão, tais como licitações em andamento, contratos e relatórios exigidos pela lei de responsabilidade fiscal.

Quadro 1 - Considerações feitas pelos acadêmicos sobre as dificuldades enfrentadas para encontrar as informações no Portal da Transparência.

\begin{tabular}{|c|c|}
\hline Categoria & Considerações dos acadêmicos \\
\hline Plataforma & $\begin{array}{l}\text { - Menu complexo; } \\
\text { - Dificuldade em acessar a plataforma; } \\
\text { - Sistema fora do ar; } \\
\text { - Acesso indisponível para alguns itens. }\end{array}$ \\
\hline Legislação & - Indisponibilidade de Leis. \\
\hline Informações & $\begin{array}{l}\text { - Não são claras; } \\
\text { - Limitadas; } \\
\text { - Difíceis de encontrar; } \\
\text { - Demonstrativos técnicos. }\end{array}$ \\
\hline
\end{tabular}

Fonte: Dados da pesquisa (2018). 
Conforme pode-se observar no quadro 1, outro aspecto levantado pelos acadêmicos é a questão da legislação. Conforme um dos acadêmicos respondeu "algumas leis não estavam disponível”, outro disse que a sua dificuldade foi encontrar "informações a respeito de Leis", ou por indisponibilidade ou por dificuldade de acessibilidade do Portal da Transparência.

\section{CONSIDERAÇÕES FINAIS}

De acordo com a análise e os resultados da pesquisa apresentados, conclui-se que, o nível de participação cidadã entre os acadêmicos no que se refere ao controle social e fiscalização da gestão pública é baixo. Foi possível perceber ainda, que quando o acadêmico tem de certa forma algum contato com as questões públicas, ou por ser funcionário público ou por ter cursado disciplinas que abordassem a gestão pública, esse nível melhora.

Portanto, sugere-se que, para uma formação que além de acadêmica, seja cidadã, desenvolvase ao longo dos cursos, trabalhos que envolva o Portal da Transparência de maneira que, proporcione ao acadêmico o contato com a temática, e contribua para o fortalecimento da prática do controle social.

Ainda, conforme mostram os resultados da pesquisa, um dos fatores que dificulta a prática do controle social é a barreira técnica em que o acadêmico se depara. Pois, os mecanismos criados para disponibilizar as informações da gestão pública, seguem padrões técnicos que demanda de um mínimo de conhecimento para extrair as informações desejadas. Portanto, pode-se concluir que, é baixo o índice de acadêmicos que não apresentaram nenhuma dificuldade em obter as informações pesquisadas no Portal da Transparência, implicando no nível do controle social. O que reforça mais uma vez, a necessidade de colocar o acadêmico em contato com esses mecanismos, sendo o Portal da Transparência um deles.

Como sugestão para futuras pesquisas, indico que se faça uma análise do Portal da Transparência do Município de Nova Mutum e verifique se o mesmo atende às exigências legais, e ainda, se as dificuldades encontradas pelos acadêmicos são consequências de falha do Portal ou se é falta de conhecimento técnico do acadêmico.

\section{REFERÊNCIAS}

ANDRADE, Daniela Meirelles; CASTRO, Carolina Lescura de Carvalho; PEREIRA, José Roberto. Cidadania ou "estadania" na gestão pública brasileira? Rev. Adm. Pública vol.46 no.1 Rio de Janeiro Jan./Feb. 2012. Disponível em: <http://www.scielo.br/scielo.php?script=sci_ arttext\&pid=S0034-76122012000100009>. Acesso em: 09 jul. 2017.

CRUZ, Cláudia Ferreira et al. Transparência da gestão pública municipal: um estudo a partir dos portais eletrônicos dos maiores municípios brasileiros. RAP — Rio de Janeiro 46(1):153-76, jan./fev. 2012. Disponível em: < http://bibliotecadigital.fgv.br/ojs/index.php/rap/article/view/7080>. 
Acesso em: 08 jul. 2017.

MATIAS-PEREIRA, José. Finanças Públicas: a política orçamentária no Brasil. 5. ed. São Paulo: Atlas, 2010.

NISKIER, A. LDB a nova lei da educação. 7. ed. Rio de Janeiro: Consultor, 1997.

OLIVEIRA, Maxwell Ferreira de. Metodologia científica: um manual para a realização de pesquisas em Administração. Catalão: UFG, 2011.

ZANELLA, Liane Carly Hermes. Metodologia de estudo e de pesquisa em administração. 2. ed. reimp. - Florianópolis: Departamento de Ciências da Administração / UFSC, 2012. 